\title{
CARTAS DA JANELA
}

Manlio M. Speranzini*

Ano: $2007 / 2015$

Dedicatória: Para M. (de Márcia)

Não há mais o que esclarecer a não ser apontar os caminhos e, se o resultado final não guarda qualquer lucidez, é porque, de outro modo, não seria coerente com aquilo de que se trata: a insensatez. $\mathrm{O}$ trampolim e a areia movediça da pesquisa foi Como viver junto, de Roland Barthes - livro que não é livro, mas Infratexto - um estado de discurso que precede o texto (Éric Marty). O ensaio aqui assume o NãoMétodo explicado por Barthes como, entre outras coisas, um tratado excêntrico de possibilidades, um titubear entre
Doutorado em Letras (FFLCH/USP), Mestrado em Estética e História da Arte (EHA/USP), Arquiteto de formação (FAU/USP), e artista gráfico de profissaao. Realizou duas exposiçoes individuais: Iuz, UNICID, São Paulo (2001). mantio@ig.com.br

blocos de saber. Obra dentro da obra, de Como viver junto pula-se para La séquestrée de Poitiers, de André Gide: no dia 22 de maio de 1901 uma carta anônima denuncia: uma moça presa num quarto há 25 anos pela família. A polícia invade o local e resgata a vítima encontrada deitada nua sobre um colchão de palha. 52 anos, de magreza pavorosa e cabeleira compacta, grossa, não fala coisa com coisa. $\mathrm{O}$ ar é fétido. $\mathrm{O}$ Juiz de Instrução envia a sequestrada ao Hospital. Ainda o Não-Método: partir de uma fantasia, desejos, imagens que rondam, que se buscam em nós e só se cristalizam através de uma palavra - significante maior que induz da fantasia à sua exploração. Sua exploração por diferentes bocados de saber 
= a pesquisa. "A fantasia se explora, assim, como uma mina a céu aberto”, escreve Barthes em suas anotações de aula. Viver junto: num mesmo lugar e no mesmo tempo que... = contemporaneidade. Eu no tempo dela, ela no meu tempo: com-partilha-o-momento. Ah, ma pauvre Mélanie! (Seu nome verdadeiro era Blanche, mas Gide escolheu para ela o que lhe era o oposto: Mélanie, variante de 'Melana', nome que deriva do termo grego melanos: escuro). Um destino pode ter cor? Fantasia: cenário, um misto de imagens, uma paisagem, um olhar e um corpus literário. A História de Mélanie que, no curso de Barthes, é o conflito, a contradição e a desordem. O lugar-problema: o quarto - estrutura reduzida à cama. Os objetos sinalizadores de territorialidade são os dejetos. Objetos = Dejetos. Se a clausura é o espaço de segurança onde o privado é a demarcação de um território a ser preservado, no caso de La séquestrée de Poitiers o quarto é o lugar a ser evitado: mal-estar, mau cheiro, loucura, clausura e perguntas sem resposta. O que separa o cuidado, o afeto e o desapego do desinteresse e da maldade? Como justificar tamanho castigo? Cadeado nas janelas, frestas obstruídas da persiana. "Mélanie não fala coisa com coisa", repete a família. Filia (propositivo, do grego, philos - amigo, querido) x Fobia (medo). Deserto: clausura expansiva. Não existem obstáculos a serem vencidos, toda a paisagem é um único obstáculo: monótono, indiferenciável, infinito. Barthes reconhece aí a figura do cobertor que Mélanie usa para se cobrir e se esconder. Lugar da catatonia. Flores são um elemento surpreendente pelo seu valor simbólico. Ele lembra que Mélanie, ao ser recolhida ao hospital, se alegrava ao receber flores e sabia o nome delas: "[...] quando a coisa é 'óbvia', é então que se deve atentar para ela. O 'óbvio' comporta muitas perguntas sem respostas”, afirma Barthes e define: 'Flores' - o que está além ou aquém da fruta útil e só pode existir numa economia do luxo; símbolo ativo do 'para nada', coisa inútil; coisa rara; a flor como oferenda religiosa; objeto integrado nas práticas simbólicas - o buquê. Coisa colorida, a flor, figuração civilizada da pulsão: delicada, frágil e perecível. O quarto de Mélanie: uma História da sujeira. O sentido do excremento no quarto de Mélanie: um espaço

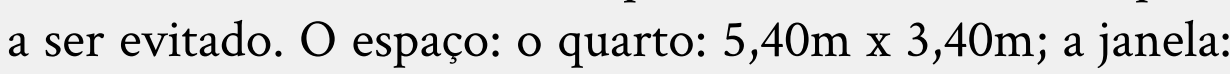
$1,60 \mathrm{~m}$ por $0,98 \mathrm{~m}$; o soalho corroído; um buraco por onde passam ratos. O mobiliário e os objetos: uma cômoda sem gavetas, duas estantes de madeira branca, quatro garrafas vazias, três frascos de conserva, um jogo de loto, duas porcas, uma estatueta da Virgem, uma cama de ferro, lençóis, cobertas, trapos velhos e sujos, a armação de um sofá, seis cadeiras de palha, uma cama de madeira, um colchão podre de palha, um lençol dobrado em quatro, um travesseiro velho, um cobertor imundo, um quadrado de linóleo, uma pequena caixa de livros velhos. As paredes foram em outros tempos cobertas por um papel azul-acinzentado com quadrados marrom e azul escuro. Inscrições nas paredes. Ainda
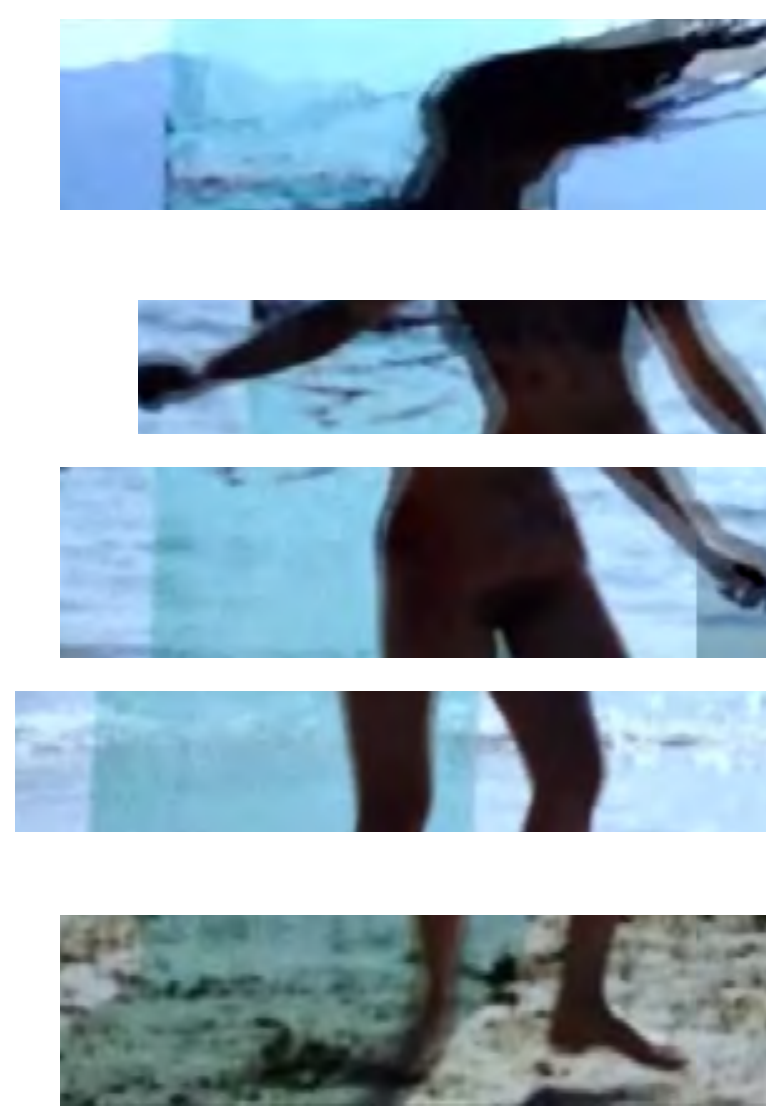


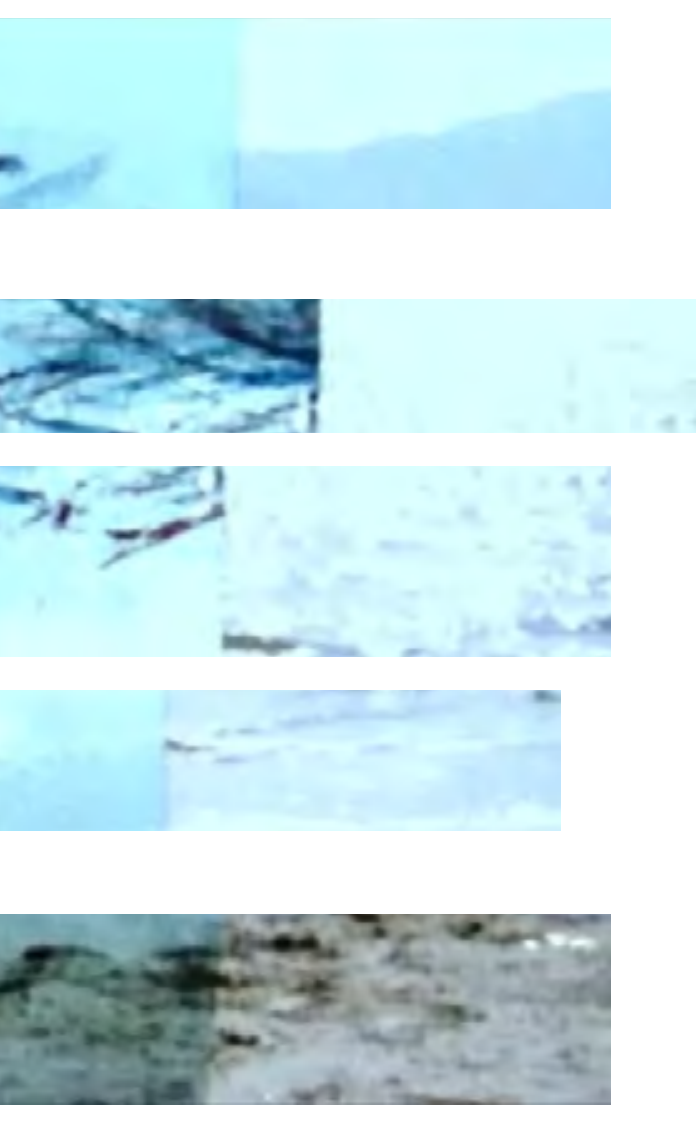

que a maioria seja indecifrável, uma delas ainda permite que se leia: "Fazer a beleza, nada de amor e de liberdade, solidão sempre. É necessário viver e morrer no calabouço toda a vida". Walter Benjamin e a experiência traumática: a incapacidade dos traumatizados em formular um sentido para o ocorrido - a ruptura, a fenda, a desconexão entre o que eram antes, o que são agora e o que serão depois. A incoerência das experiências desmoralizadoras: a Guerra, a Fome, o Desemprego e a Corrupção. O terreno da não-experiência - uma nova barbárie. E a loucura, e o desvario? "Resta o sonho noturno", consola Benjamin. Viver de olhos fechados. Narrar, para Benjamin, é a faculdade de intercambiar experiências. A fonte da narrativa é a experiência passada de pessoa a pessoa. $\mathrm{O}$ narrador então retira da experiência vivida o que ele conta: sua própria experiência ou a relatada por outros, aquela que ele sabe por ouvir dizer, incorporando as coisas narradas à experiência dos seus ouvintes e permitindo a pergunta: e depois? Ah, ma pauvre Mélanie! O narrador. O romance, ainda que anuncie a perplexidade de quem vive um sentido da vida não permite que se ultrapasse o limite da palavra 'Fim'. Mélanie não sabe o que é 'fim' nem 'começo' - está sempre no meio... Para Benjamin, contar histórias sempre foi a arte de contá-las de novo e tanto mais poderosa é uma narrativa quanto mais ela ainda for capaz de suscitar espanto e reflexão. Ah, ma pauvre Mélanie! Contar de novo. Contar outra vez. A mãe e o irmão de Mélanie são presos.
Mélanie passava a ser assistida pelas freiras e médicos da instituição. Sua fotografia, tirada na cama do hospital logo depois da sua chegada, é reproduzida em diversos jornais ilustrados da época: Mélanie pesava então $25,5 \mathrm{~kg}$, tinha o rosto de uma brancura de cera, o corpo cheio de placas de sujeira, unhas muito compridas e os cabelos formando uma massa compacta de mais de metro. No momento do seu resgate, ela gritava que não a tirassem da sua 'grutinha'. Depois de um tempo no hospital, limpa e com a cabeça raspada, ela demonstrava algum prazer em estar arrumada e respirar ar puro. Após dois meses de cuidados intensivos ela pesava $35,5 \mathrm{~kg}$. Apesar das melhorias aparentes, ela ainda se mostrava indiferente ao que se passava a sua volta e raramente tomava a iniciativa de falar alguma coisa ou de fazer perguntas, passando a maior parte do tempo emitindo sons incompreensíveis. Descobriram que gostava de flores. Ela começou a se referir aos objetos que lhe apresentavam fazendo uso do diminutivo e acrescentando 'querido' ou 'querida': meu lapisinho querido... minha rosinha querida... Embora ela se esforçasse em escrever com clareza, tudo o que escrevia terminava em rabiscos sem sentido. Gostava do perfume de flores, da água de colônia que passavam em seu corpo todas as manhãs e de tudo aquilo que apresentasse uma cor clara, que fosse brilhante ou luminoso. Ah, ma pauvre Mélanie! A mãe dá seu depoimento à polícia: "Nunca pensei em sequestrar minha filha, que eu amava tanto". "Ela sempre teve 
uma saúde muito delicada... Mesmo assim, ela pôde fazer seus estudos. Ela gostava do trabalho e em especial da leitura". "Ela não era louca, mas tinha comportamentos estranhos. Não queria dormir sob os lençóis, recusava vestir uma combinação...". "O médico não vinha vê-la porque ela não estava doente”. A mãe morreu na enfermaria da prisão sem ser julgada e negando sempre qualquer responsabilidade pelo sofrimento mental e físico da filha. Momentos antes da chegada do médico que atestaria sua morte, ela teria gritado: “Ah! Ma pauvre Mélanie!”. À pergunta: “como se faz no animal-homem uma 'memória' - esse entendimento-de-instante - a quem tem aptidão ao esquecimento?" Nietzsche responde: "na dor". A justifica para isso, acrescenta: é que "somente o que não cessa de fazer mal permanece na memória" visto que "nunca, nada, se passou sem sangue, martírio sacrifício, quando o homem achou necessário se fazer uma memória”. A origem para isso encontra-se no instinto que adivinha na dor o mais poderoso meio auxiliar da memória, afirma o filósofo. É fazendo de certas ideias, ideias fixas, inextinguíveis, onipresentes e inesquecíveis, que o ser humano, tomado por esse incômodo, não tem forças para se livrar de tamanha pressão: mais do que buscar uma solução para o seu tormento, esse homem não deixará de pensar um só instante naquilo que o aflige. Nietzsche reconhece no castigo duas instâncias que o colocam ora como sendo duradouro, ora como fluido. É duradouro nele o uso, o ato, o drama. Já, fluido, é o fim e a expectativa vinculada à sua execução. O conceito de castigo é então uma síntese de sentidos, uma espécie de unidade indefinível que torna impossível dizer a razão correta que justifica a natureza do castigo, e afirma: "Definível é somente aquilo que não tem história". Des pleurs amers. $\mathrm{O}$ artista escrevedor. Vários artistas, afirma Bayer, vêm há um bom tempo se aproximando de conteúdos e procedimentos antes restritos ao campo da escrita para conferir uma qualidade literária a uma arte do espaço. A visualidade da arte contemporânea, continua, já vinha se colocando no "cruzamento da imagem-movimento do cinema, dos princípios construtivos da arquitetura, dos elementos reflexivos da filosofia e 'narratológicos' da literatura, num exercício complexo de hibridização dos procedimentos”. Através do trabalho de vários artistas, a autora reconhece fazeres e abordagens que permitiriam entender as lógicas desenvolvidas por eles para inserir a escritura no campo da arte contemporânea, tais como: a cópia, a inclusão, a apropriação, o exercício do 'escrevedor' (scripteur), a interpolação, a ação do fabulador, as configurações narrativas e as citações. Sendo o desenvolvimento textual ser um desenvolvimento no tempo, entende Bayer, muitos artistas incorporam elementos da dimensão literária visando produzir uma obra visual que se temporaliza, permitindo então uma maneira particular de reativação do tempo e da memória. E conclui: para esses artistas "uma outra topologia da criação 
se apresenta, onde a narrativa é a feitura da obra, e a obra - a fabricação romanceada do mundo”. Tipografia: a matéria de um corpo novo para Mélanie na forma dos 3 estágios da sua recuperação: Mélanie Fraca (Light), Mélanie (Normal) e Mélanie Forte (Bold). Qu'est-ce qu'on dit? Ouvia-se que Mélanie amara e se entregara. Dizia-se que uma criança fora o fruto de seus amores. Acreditava-se ainda que essa criança lhe fora subtraída. Suspeitava-se ainda que, para puni-la por sua 'falta', fora trancada no quarto. Mas como saber? Diziase ainda que se casaria, mas o tempo passava e nada acontecia. Não saiu mais de casa. Comentava-se também que não queria se vestir e andava seminua pela casa... As janelas precisavam ficar fechadas... Não era louca, diziam, pensava direito. Também não era ruim (só com a mãe). Des lettres perdues. Durante algum tempo ela ainda pedia papel e lápis e escrevia cartas que colocava dentro de envelopes e as passava pelas frestas da persiana, contando que a empregada as recolheria e as levaria ao correio. Mas as cartas recolhidas eram entregues à mãe de Mélanie que, mesmo sem abri-las, as rasgava e as jogava fora. Outra vez. Outra vez. As frestas da janela obstruídas. Um padrão a se repetir indefinidamente... O lugar-problema. "Todos os espaços das nossas solidões passadas, os espaços em que sofremos a solidão, desfrutamos a solidão, desejamos a solidão, comprometemos solidão, são indeléveis em nós”, escreve Bachelard em A poé tica do espaço. A solidão em mim, sempre. A janela do quarto de Mélanie é uma janela cega - não abre -, trancada com cadeado e com as frestas obstruídas. Não se ouvem seus gritos. Não se vê seu corpo. As frestas da janela: um espaço de passagem para as cartas que ninguém leu, nem respondeu: “Querida Mélanie...”. Uma ideia de paisagem, uma superfície, as frestas obstruídas da veneziana. Au-delà. "Quero voltar para meu querido fundão Malampia”, repetia Mélanie em momentos de desrazão. Um outro lugar. O precário, segundo Jean Oury, é uma das palavras favoritas de Freud nos seus primeiros escritos. Ele também explica que psicose não é alienação, (todos somos alienados!, no sentido Marxista), mas é uma 'alienação psicótica'. O alienado, explica, pertenceria a um tipo de transcendência que não é a mesma do sagrado, mas que os dois (a loucura e o sagrado) teriam lugares dentro de qualquer sociedade, principalmente as primitivas. A transcendência - esse outro lugar - corresponderia ao que Freud designava como 'outro palco'. A loucura introduz um corte na relação do homem com o mundo cotidiano e esse corte dá acesso a outro lugar, definido por Oury como o lugar do pathos: "lugar da poiesis (gr.), lugar de certo tipo de criação permanente, não mais a partir de uma sintaxe toda feita, aceita na sociedade, mas a partir disso que está em jogo na própria produção de um texto. Oury chama então de 'transferência' a criação de um 'lugar do dizer' e salienta que o dizer do psicótico não pode ser recuperado numa significação ou numa interpretação como na análise 
das neuroses. A esquizofrenia faz com que haja a ruptura do lugar pela própria dissociação e a tarefa do psiquiatra é então trabalhar para ter acesso ao lugar rompido do esquizofrênico. Oh! que c'est beau! Au-delà. O estado intelectual de Mélanie não acompanha sua melhora física e mental. Seu prazer se resume a ver e cheirar flores. Oh! que c'est beau! Um sentimento de beleza: Camélias brancas. Filme KODAK 100, 36 poses, fotografia analógica, 4 exposições: as frestas da veneziana, as flores, o que dizem que Mélanie dizia no Sanatório e o que falavam dela no tribunal. Ainda que alienada, mantinha um sentido de pudor. Paroles sans valeur. "Todos esses gritos não têm qualquer significado; na boca de minha irmã, essas palavras não têm valor. Ela as pronunciava nos momentos de crise e demência. Na minha frente ela nunca pediu socorro ou reivindicou sua liberdade. Ela parecia se dirigir a um ser imaginário". Ah, Mélanie, Melanie... Escreve para mim.

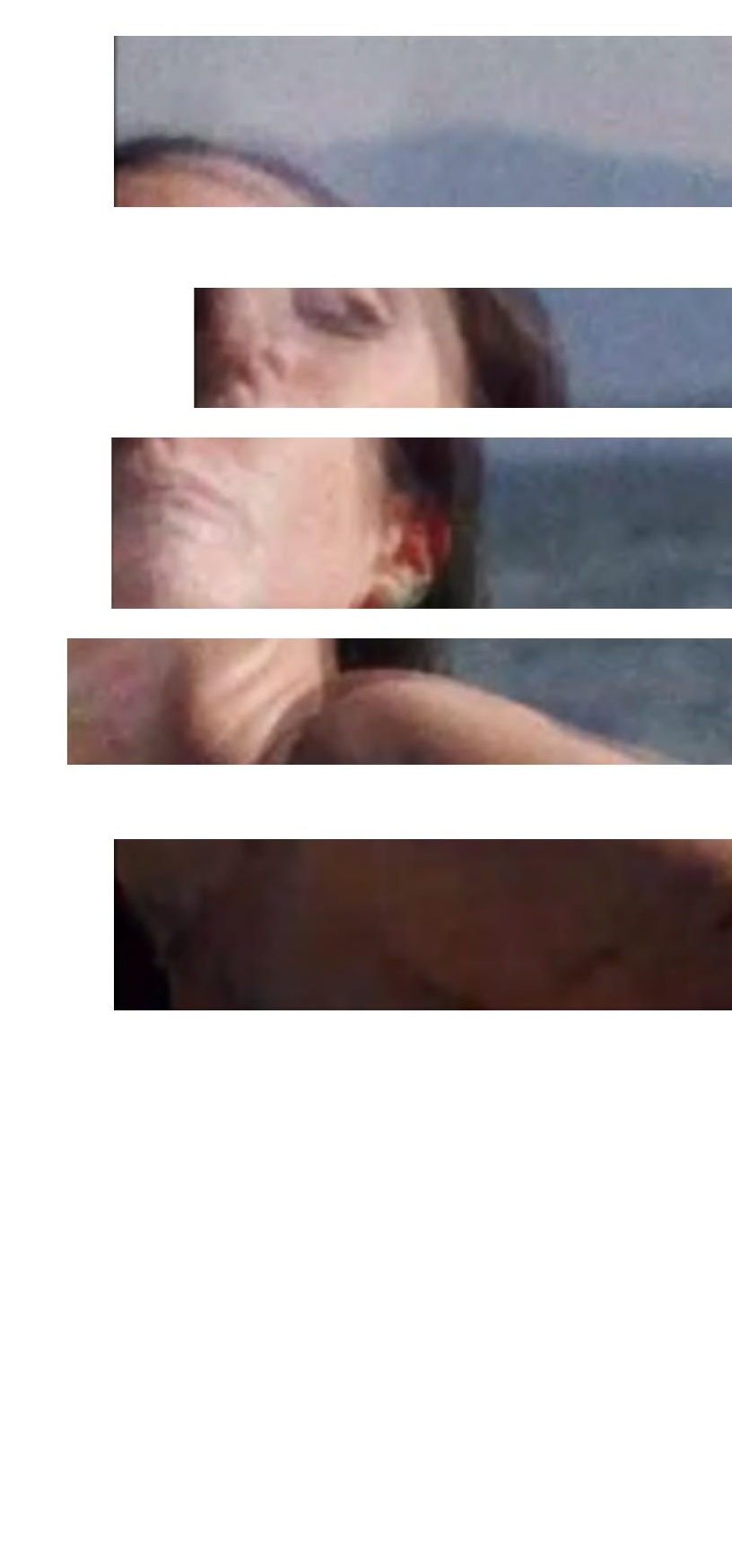




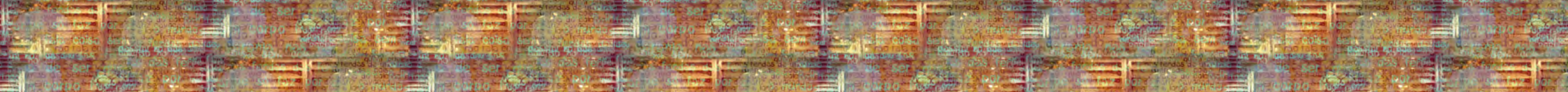
Fla

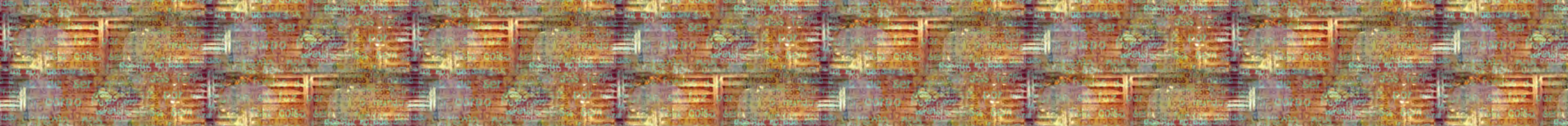
F

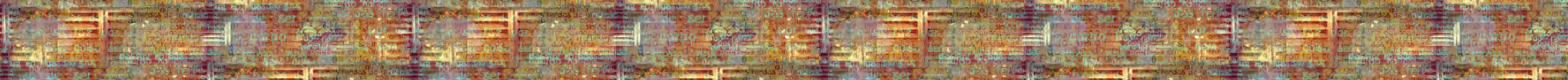

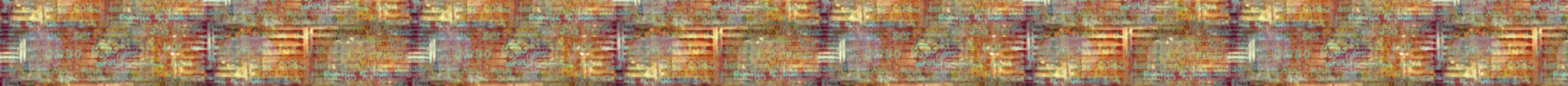
F 4 -

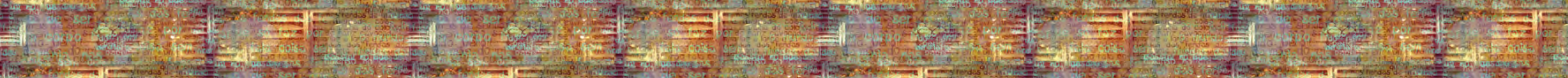

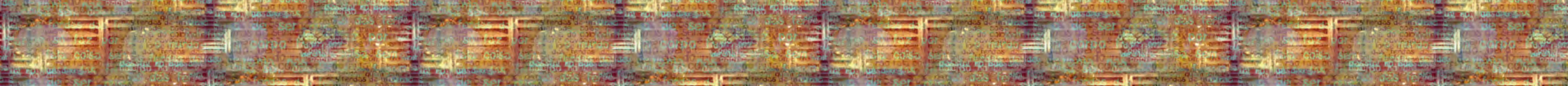

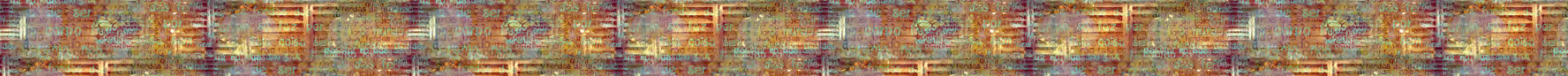
En

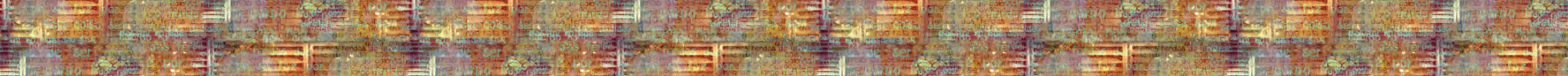

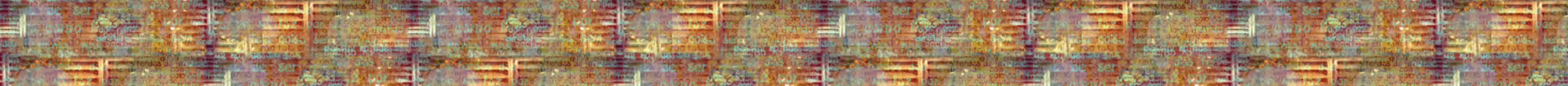
F

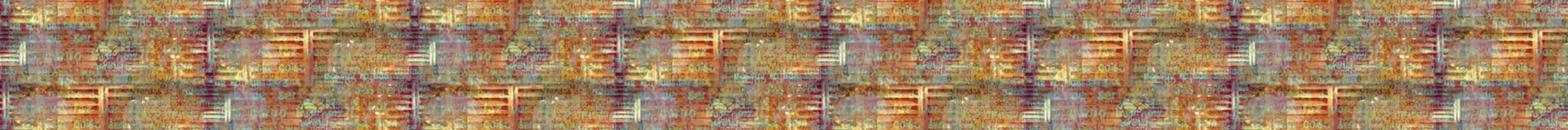

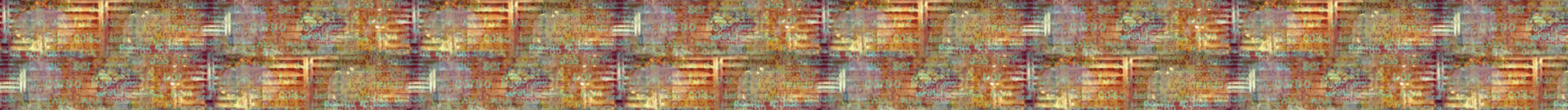
Ex

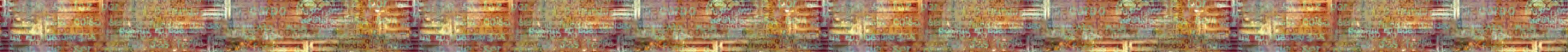






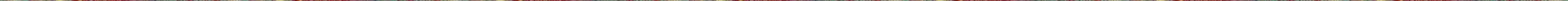


